\title{
Aggressive billing techniques confusing Canadians
}

$\mathrm{M}$

edicare advocacy groups have in recent months noticed a sharp uptick in telephone calls from Canadians wondering why they are receiving so many bills from their family doctors. Letters inquiring if patients want to pay annual block fees for uninsured services are also appearing in mailboxes with greater frequency, further adding to people's confusion about just what is and isn't covered anymore under medicare.

"Here in Alberta, I'm getting calls quite regularly about clinics charging for sick notes and facility fees or bills to cover clerical things," says David Eggen, executive director of Friends of Medicare in Alberta. "It's been an ongoing story in Alberta since early this summer. ... Has the scope of insured fees narrowed so much that doctors have to make the extra up through other fees?"

A similar story has been unfolding in Ontario, where it's been estimated that more than 2 million letters asking for block fee payments have been sent to patients on behalf of about 1000 doctors.

"We've seen an increase in calls and complaints about it," says Natalie Mehra, director of the Ontario Health Coalition. "The fees are exorbitant in some areas. People are getting letters out of the blue and don't understand it."

Proponents of universal health care are concerned that the trend of doctors levying more fees on patients is not only causing confusion, but is making people hesitant to visit their doctors.

"In the spirit of medicare, which is supposed to be about not being charged at the point of access to medically necessary services, [these fees] are a real problem," says Dr. Danielle Martin, chair of Canadian Doctors for Medicare. "And there are more and more of them sprouting up, from the very minor to the very major."

Some doctors, however, claim that Canadians have for too long been the beneficiaries of poorly run medical billing systems. Historically, physicians have been notoriously lax when it comes to billing patients for uninsured services, such as writing sick notes or completing fitness certificates. Increas- ingly, doctors are relinquishing this responsibility to companies that claim their billing services can increase annual physicians' incomes by as much as \$20 000 while reducing their workloads by about 30 minutes a day.

Healthscreen Solutions Inc., a company that offers an uninsured billing service called CallerMD, has experienced tremendous growth in the past year. For the fiscal quarter ending June 30,2008 , it reported revenues of $\$ 2.6$ million, a $275 \%$ increase from the same quarter last year.

"We're talking \$15 for most of these services," says Dr. Bruce Rosenberg, vice-president of business development for Healthscreen Solutions Inc. "You hear people saying doctors are gouging their patients, but I don't see how that's gouging. I think that's a great bargain."

Rosenberg, a family physician in St. Catharines, Ontario, claims that standardizing billing of uninsured services also benefits patients, because some doctors, freed from the burden of billing, have begun offering more uninsured services.
Practice Solutions Ltd., a subsidiary of the Canadian Medical Association, offers software products and a direct mail service for improving collection rates of uninsured services. Some 200 physicians have signed on for the company's block billing service since its inception in 2007.

"The block funding model is just a method of payment," says Tim Smith, the company's vice-president. "It gives patients options. You can pay as you go or pay with an annual fee."

But many Canadians, it seems, are none too pleased to be presented with this option. Patient advocacy groups report fielding far more complaints from people invited to pay an annual block fee than from those billed for individual services. Block fees are typically around $\$ 200$ but vary from practice to practice, depending on the number of uninsured services offered. Rosenberg claims less than $10 \%$ of Healthscreen's patients opt to pay a block fee.

Still, some patient advocacy groups, such as the Ontario Health Coalition, want them banned.

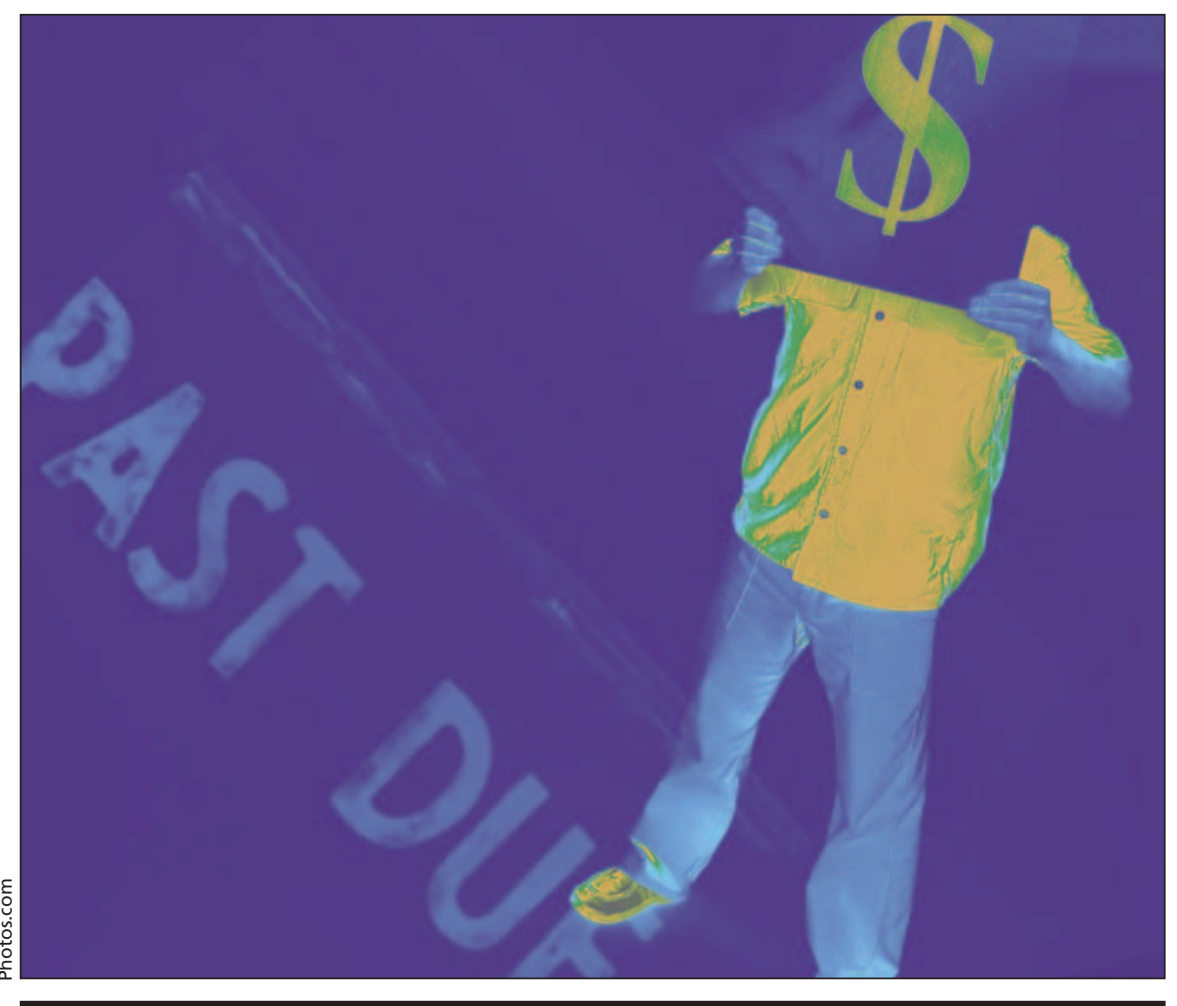

Medical advocacy groups say they're being inundated with complaints from Canadians about annual block fees and other charges for uninsured services. 
"These amount to user fees, and the fees are not returned to people who don't use the services," says Mehra. "Physicians are prohibited from extra billing, and this is just a loophole for them to pay for their overhead without proper tracking of usage. Patients are afraid not to pay because they think it will mean less access to their doctors."

Other health care experts believe it's important to distinguish between fees for medically unnecessary services, such as the renewal of a prescription by telephone, and fees for services that may be uninsured but are nonetheless vital to the provision of medically necessary procedures.

Marie-Claude Prémont, an expert in health care law and a teacher at École Nationale d'Administration Publique in Montréal, Quebec, refers to the latter type as accessory fees. Some doctors, for example, require that patients pay to see a dietician before having a colonoscopy or charge a fee for cleaning colonoscopes.

These fees are the true barriers to accessible health care, says Ms. Prémont, not the ones for services that patients want but don't absolutely need. "There is no reason why the public should pay for your cosmetic surgery or if you need a check-up so you can go hiking in Tibet."

Patients may be facing more fees in general because a shift from hospitalto community-based health care has occurred without a corresponding shift in how services are funded. Many medical procedures, such as knee and hip replacements, were once offered only in hospitals, where accessory services are covered by global budgets. Now they are increasingly being offered in clinics that only receive funding for insured services.

"We can't say to a physician that it's wrong to charge for an uninsured service," says Martin, a family physician. "But we can't forget what the spirit of the public system is supposed to be about, which is when you show up in need of health care, you don't get asked to open your wallet. These things are nibbling away at the edges of that." Roger Collier, CMAJ

DOI:10.1503/cmaj.081539

\section{Health infrastructure a casualty of war on terror within Pakistan}

A rguing that the health infrastructure in the Federally Administered Tribal Area of Pakistan has been one of the biggest casualties of the "war on terror," the nation's medical association is asking the international medical community to join them in decrying the targetting of health facilities by the United States and Pakistani forces.

"It is an inhuman act on the part of the US and Pakistani forces to target hospitals and deprive the patients of the healthcare facilities. We demand an immediate halt to the dropping of bombs on hospitals," says Dr. Abdul Qadir, president of the Pakistan Doctors' Association.

Since the beginning of the US-led war against terrorism in Pakistan in 2005, there have been attacks on several health facilities in the Federally Administered Tribal Area, which comprises 7 tribal agencies and 6 frontier regions that are collectively bordered on the west by Afghanistan, and on the south and east by Pakistan's Balochistan and NorthWest Frontier provinces, as well as the Indian state of Punjab. The Tribal Area is nominally controlled by the central government of Pakistan and comprised primarily of Pashtun tribes.

In the aftermath of the war in Afghanistan, launched by the US and the United Kingdom with the stated purpose of removing the Taliban regime which had provided safe harbor to Osama bin Laden and al-Qaeda, the remnants of the former Kabul government and its supporters took refuge in the Tribal Area.

In its bid to flush out members of the Taliban, the US has been attacking the Tribal Area, causing unrest among its 3.6 million residents and a lengthy parade of medical casualties.

In September 2006, surgeon Mir Wali Shah and 3 vaccinators were killed by US missile fire over a Tribal Area hospital.

Qadir says many doctors are reluctant to be in the Tribal Area's health facilities and as a consequence, many have taken long leaves of absence or sought transfers to safer facilities.

The Tribal Area, Qadir says, had a

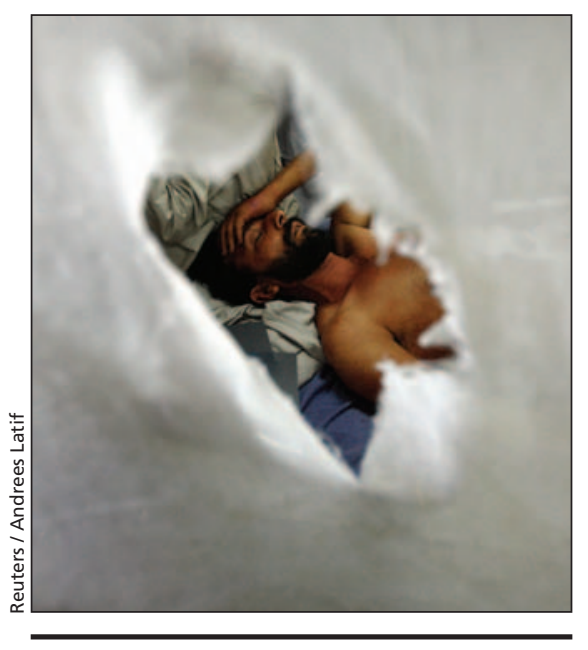

A resident of the North Waziristan town of Bannu, seen through a hole in a sheet at his bedside, is treated for injuries received as a result of rockets fired by militants.

good health-delivery network before 2005 but now is so debilitated that even patients needing minor procedures are brought to Peshawar (the capital of the North-West Frontier Province) for treatment.

Typical is Wajid Khan, who brought his brother Sajid, to the Khyber Teacher Hospital in Peshawar for an appendectomy. "We live very close to the agency headquarters hospital, in Miramshah, North Waziristan Agency, but due to the nonavailability of doctors and staff, we brought our brother here," he says.

Others worry about the strain of added travel.

"We had a full-fledged government hospital in Bajaur Agency. But we transported our mother to Peshawar because of the nonavailability of a specialist there," says Gul Khan, claiming to have paid 1000 rupees (US\$16) for a 3hour taxi ride to transport his mother, who was suffering from hypertension, from the town of Bajaur to Peshawar.

Dr. Zubair Khan, director of Health Services in the Federally Administered Tribal Area, says that since 2002, the number of admissions in hospital and out patient departments has declined dramatically.

Medical Officer Dr. Amjad Ali adds 